\title{
Retrofitting Generic Graduate Attributes: A Case-Study of Information Systems Undergraduate Programs
}

\author{
Mark Toleman, Dave Roberts, Charmaine Ryan \\ University of Southern Queensland, Toowoomba, Australia
}

\author{
markt@usq.edu.au roberts@usq.edu.au ryan@usq.edu.au
}

\begin{abstract}
This paper discusses how a set of 'mandated' generic graduate attributes were incorporated, by a retrofit, into an IS undergraduate degree program. The current challenge is to implement these attributes completely by matching them to course objectives, by explicitly including and assessing them, and by refining teaching and learning strategies to be cognisant of them. Other considerations identified are the extent to which these attributes actually suit the needs of IT/business graduates (including those contemplating postgraduate study), employers of IS graduates, and professional bodies. Attributes not addressed in the generic set are also considered as are attributes students possess prior to beginning degree studies.
\end{abstract}

Keywords: Generic Graduate Attributes, Generic Attributes, Graduate Attributes, Information Systems Graduates, Assessment, Information Systems Curriculum

\section{Introduction}

There are many groups with varying expectations of the attributes of university graduates. Employers are one group requiring graduates with high level skills and various attributes. Professional bodies and associations often stipulate specific requirements of graduates wishing to enter their respective professions. Universities mainly view graduate attributes as outcomes from their teaching and learning strategies but they also want appropriate graduates for postgraduate programs some including research. The students themselves (and their families) assume they will have various skills, knowledge and competencies on completion of their program (also referred to as degree or course at various institutions). Whatever the stakeholder, there are expected attributes of a graduate not always in synchronisation for all the stakeholders and not always satisfied.

Obviously universities play an important (pivotal/critical) role in the development of graduates. Therefore it is not surprising that publicly funded institutions find they are increasingly required by government, as the main source of funds, to be accountable for their outputs. Universities are expected to produce graduates with various generic attributes as well as discipline-specific attrib-

Material published as part of this journal, either on-line or in print, is copyrighted by Informing Science. Permission to make digital or paper copy of part or all of these works for personal or classroom use is granted without fee provided that the copies are not made or distributed for profit or commercial advantage AND that copies 1) bear this notice in full and 2) give the full citation on the first page. It is permissible to abstract these works so long as credit is given. To copy in all other cases or to republish or to post on a server or to redistribute to lists requires specific permission from the publisher at Publisher@InformingScience.org utes. In the Australian context university administrations are required, as part of their annual reporting to government, to provide details on the means by which they achieve their stated aims in this regard. Clearly then there are statutory requirements of universities but it is wider than that. 
Most universities make public statements about the generic and discipline-specific attributes of their graduates, in particular using the Internet to provide these. Some universities make public the ways academic sections can map their current curriculum to adopted graduate attributes (for example, Murdoch, 2003). Some universities publish course (also referred to as subjects or units at various institutions) specifications including how attributes are mapped to individual courses. For example, courses at Edith Cowan University (ECU, 2003) specify in their course outlines the graduate attributes to which the course contributes. DEST (2001a) has published a list of Australian universities where graduate attributes are documented. Of course, not all stakeholders necessarily consider the articulation of sets of broadly-based generic attributes as worthwhile. For ex-

ample, Yu, Hume, Lee, \& McConkey (2002) in their submission to the Higher Education Review Process for the University of New South Wales cautioned against the testing of such attributes outside the context of the discipline studies. Such testing has been advocated by the Australian Government (DEST, 2001b).

Specifically related to information systems (IS) and graduate attributes, Nunan (1999) indicated the need for more attention to be paid to graduate attributes in the management information systems area (at least by some institutions in the United Kingdom). Snoke, Underwood and Bruce (2002) considered generic attributes coverage of an information systems curriculum at the Queensland University of Technology (QUT) and compared this with expectations of professional bodies. Indeed these QUT researchers have been very active in assessing both academic and industry views of generic attributes considered desirable in IS graduates (Snoke \& Underwood 1998, 1999, 2001). These studies reveal differences in opinion between academics and industry representatives in relation to the importance of various attributes. The research reported in Snoke et al. (2002) is important because it investigates the correlation between the curriculum objectives of programs at a university and the generic attributes required by professional bodies who are certainly one of the key stakeholders.

This study is primarily concerned with explaining how a set of generic graduate attributes, 'mandated' by USQ's Academic Board, were incorporated in an IS undergraduate degree program at an Australian university: the challenges faced already and the challenges ahead. The attributes developed were intended to be covered by all undergraduate programs at the university and not just IS programs. This raised many issues some of which are considered here including: how to fit the attributes to current programs and the validity of the fitting, future assessment of attributes, the range and suitability of attributes selected, and the relevance of these attributes to the various stakeholders.

This paper proceeds as follows. Firstly the historical background related to the introduction of generic graduate attributes at the USQ University (USQ) is related. This is followed by the implementation approaches adopted and then the research approach used in this study. Next the many issues raised by respondents to this exercise are discussed and finally conclusions are drawn and pointers made to further research possibilities and progress.

\section{Historical Background}

This historical background is detailed but necessary to contextualise the introduction of generic graduate attributes to USQ. It shows that political and educational issues drove the process of attribute development, incorporation and maintenance, and in this case the process is far from complete. Similar histories are likely to be found at many Australian universities.

In 1998 the Commonwealth Department of Employment, Training and Youth Affairs (DETYA), now Department of Science, Education and Training (DEST), based on its study into employer satisfaction with graduate skills (DETYA, 1998) notified all Australian Universities that as part of their reporting requirements they needed to provide a Quality Assurance and Implementation 
Plan. This document needed to include information related to the attributes of graduates exiting that university. Most universities, including the University of Southern Queensland (USQ), developed an initial list of attributes based on examination of their curricula, sets of attributes available from other universities (world-wide) and lists of attributes expected of graduates by employers and employer organisations. This initial list of fifteen attributes was developed by the university's Planning and Statistics Unit (USQ, 1999).

During 2000 this initial list was reviewed by many individuals at the university and several groups and committees including the Deputy Vice-Chancellor (Academic), Faculty Deans, Associate Deans (Academic) in each faculty, the Academic Program Committee and Vice-

Chancellor's Committee. In early 2001, the Academic Program Committee (APC) recommended a new list of thirteen graduate attributes (see Appendix) to the Academic Board and these attributes were accepted for immediate implementation in relation to Undergraduate programs containing at least 24 credit points (at least three years of full-time study).

Prior to accreditation, implementation and delivery, all undergraduate (Bachelor) degree programs at the university must pass through a rigorous accreditation process developed by Academic Board, including approvals at faculty and university level. Before the development of the graduate attributes, all undergraduate programs required students to complete (or be exempted from on the basis of prior study) a compulsory Core Curriculum which included studies in communication, computing and information communication technologies, and Australia and its Region. From 2001, accreditation (and reaccreditation) submissions needed to include a description of the means by which the program satisfied the 'Attributes of a USQ Graduate', as specified in the Program Accreditation Procedures (Part 4.2) in the USQ (2004). In effect, the graduate attributes had replaced the core curriculum although it remained possible to use core curriculum courses to fulfil some graduate attributes.

In a recent audit report (AUQA, 2002) the Australian Universities Quality Agency noted the introduction of graduate attributes into the accreditation process but also that the process had some way to go in terms of full 'inculcation of these attributes into the university's teaching and learning, in terms of content and activities' and, in particular, noted that 'assessing attributes is yet to be tackled'. The report also noted this process would be time consuming but indicated that a model for this was already available in the reaccreditation documentation of the Bachelor of Engineering which had been reaccredited in 2001. Essentially, the approach taken by the Faculty of Engineering was to utilise the attributes required of graduate engineers by the Institution of Engineers Australia, map these onto those generic attributes required and show where these attributes were developed in the curriculum and how they were assessed in the courses of the degree programs. More recently, in 2003, the Bachelor of Education from the Faculty of Education was reaccredited. The documentation explicitly addressed attributes required of a graduate by the Statebased Department of Education's Board of Teacher Registration prior to acceptance of graduates as practicing teachers. Similar to the engineering situation, these attributes were then mapped back to the university's attributes. A workshop for Heads of Department was held in early 2003 to consider fuller inculcation of the graduate attributes into all programs, particularly where external accreditation was not required or voluntary. This was the first such workshop and it was intended as an awareness raising session related to potential future requirements.

The Assessment Working Party, a sub-committee of APC, has recently reviewed assessment regulations and one recommendation is for the establishment of explicit linkages between course objectives and assessment items so that students are clear about which objectives are being assessed in each assessment item. These linkages may be very specific or broadly based on the objectives relating to a module or a set of topics in a course. Academic Board has accepted this recommendation and from 2004 all courses must provide within their student materials, details of the criteria used to assess each item of assessment and the relationship to objectives. In addition a 
Working Party of APC was established in July 2003 to review the issues associated with implementation of the graduate attributes through all the university's courses and programs. A future possibility, currently being canvassed by the Associate Deans (Academic) and the Quality Advisory Committee, is a further linkage from objectives to the generic graduate attributes.

Also, necessarily there is ongoing review of the current list of attributes (although the July 2003 meeting of Academic Board reaffirmed the current set) through these same committees, with a view to advising APC and ultimately the Academic Board of potential variations. One external influence was the recent audit report (AUQA, 2002) which expressed that its panel was 'surprised to find that an international perspective... was not in the list of graduate attributes...'. Universities have a responsibility as part of the audit process to consider the issues raised by any audit report even if to argue they are not appropriate at that time.

\section{Implementation of Graduate Attributes}

The Bachelor of Information Technology (BIT) was first accredited by the university's accreditation processes in 1992. Two of its information systems majors (Business Programming and IT Management) were subsequently also accredited by the Australian Computer Society (ACS) and given appropriate Accreditation. The BIT has since been re-accredited by USQ twice, with the latest accreditation of three information systems majors (Computer Software Development CSD, IT Management - ITM and Electronic Technology - eTech) occurring in 2001. Thus, the program is not due for re-accreditation by the university for some time but it is due for reaccreditation by the ACS and this process is expected to occur shortly.

Curriculum design for IS programs at the university has been led and coordinated by senior academics in the Department of Information Systems with academic advice and administrative assistance from faculty level through the Associate Dean (Academic). The programs call on sources outside the university such as the Association for Computing Machinery (ACM) and ACS for appropriate content input to the programs developed. All specific courses require a rationale for their existence, synopsis, objectives and topics as well as appropriate assessment items. Staff teaching these courses are expected to be appropriately qualified with tertiary level qualifications (at least master's level preferred).

From 2001, the university required all currently accredited undergraduate degree programs to describe how a newly developed set of generic graduate attributes adopted by the Academic Board were being addressed. Prior to this no degree programs had addressed nor been required to address any set of generic graduate attributes in any explicit manner. Most faculties lead by their Associate Dean (Academic), including the Faculty of Business which offered the BIT in its Department of Information Systems, engaged in this retrofitting process since their programs had been accredited some time previously (the accreditation/reaccreditation process is normally a seven-year cycle). The retrofitting process involved consideration of each course/subject and noting (by the examiner of the course) whether or not the stated graduate attributes were covered by the content, teaching methods and assessment instruments used. This was a relatively superficial process since only the presence or absence of graduate attribute coverage was considered; not all attributes were covered by each course (not required) and some attributes were covered more comprehensively than others (not considered an issue at this stage). Table 1 shows USQ's graduate attributes (in the order as presented in the Appendix) and number of courses contributing to each attribute for the core of the BIT and the three IS majors of the BIT (a minor of four courses will be taken with the CSD and eTech majors and a second major of eight courses is usually taken with the ITM major, totalling 24 courses in all for all program structures). All faculties have now assessed their undergraduate degree programs and all have met requirements that their programs contain at least content and teaching methods to cover the graduate attributes. 
As indicated above, the requirement for assessment instruments to show a linkage to graduate attributes is still under consideration. However, examiners of all university courses are already beginning to explicitly relate course objectives to specific assessment items and advising students of these linkages through the study materials for their courses.

Table 1: Number of courses contributing to each graduate attribute for the core and each major of BIT.

\begin{tabular}{|c|c|c|c|c|}
\hline & Core & CSD & ITM & eTech \\
\hline Discipline & 7 & 12 & 8 & 12 \\
\hline Thinking & 7 & 12 & 8 & 11 \\
\hline Problem & 8 & 12 & 8 & 11 \\
\hline Independence & 6 & 11 & 7 & 11 \\
\hline Communication & 8 & 12 & 8 & 12 \\
\hline IT Literacy & 6 & 12 & 8 & 12 \\
\hline Numeracy & 6 & 7 & 4 & 4 \\
\hline Acquisition & 7 & 11 & 8 & 9 \\
\hline Decision-making & 7 & 11 & 8 & 12 \\
\hline Ethics & 6 & 12 & 8 & 12 \\
\hline Responsibility & 6 & 12 & 8 & 12 \\
\hline Life-long Learning & 5 & 11 & 7 & 10 \\
\hline Social & 6 & 10 & 7 & 9 \\
\hline Maximum Courses* & 8 & 12 & 8 & 12 \\
\hline
\end{tabular}

\section{Research Approach for this Study}

This section follows the format used for describing case studies as suggested in Asmussen and Creswell (1995). We began our study soon after the retrofit of generic graduate attributes was completed. Our study was limited to reactions at USQ. Such bounding is consistent with a qualitative case study approach as suggested by Yin (1994) and appropriate given the lack of models or constructs related to retrofitting generic graduate attributes to existing curriculum, in this case IS curriculum.

Data sources for this study were many and various (multiple) and included primary and secondary sources. Primary data included that used in retrofitting the attributes to courses and programs. Semi-structured interviews were conducted with seven senior academics and managers of USQ including the Chair of the Academic Board, Manager of the Planning \& Statistics Unit, Manager of the Secretariat, Associate Deans (Academic) in three faculties of the university, and the Director of Student Services. In addition the authors held positions on various bodies in the university 
including Deputy Chair of the Academic Board, Chair of the Program Review Committee and as Heads of Department. Questions included: What was your understanding of the history of the implementation of graduate attributes at USQ? What was your faculty's approach to implementation of graduate attributes in your programs? What are the wider ramifications of implementing graduate attributes? What are the benefits of implementing graduate attributes? What are the implications of implementation of generic graduate attributes for attributes and skills expected in specific disciplines? Secondary data sources included internal documents such as the Annual Survey of Graduates $(2000,2001)$ and various documents maintained by the Secretariat.

The issues discussed next reveal our interpretations of the views of the respondents. These views were developed with verifications from selected informants and incorporation of their feedback. Questions raised include those from respondents and our own.

\section{Issues for Discussion}

In an era of quality audits and an environment demanding accountability it is not surprising that a range of stakeholders in the tertiary education sector are demanding evidence for any claims made. The question of the relevance of graduate attributes to the various stakeholders is critical. Retrospectively fitting a set of generic graduate attributes to existing degree programs has caused many problems and raised many issues and some concerns at this university. From a corporate perspective this is a case of 'change management' - change has been managed if you were told about it! This situation is likely to be repeated at other tertiary institutions so it is worth considering these problems and issues in some depth. Few of the issues and questions raised are easily dealt with or answered; at this stage the purpose is to raise them and call for debate and further research.

Programs are comprised of a number of courses (24 in a typical three-year undergraduate degree) and indeed it is within the courses, rather than the degree as a whole, where the content, teaching methods and assessment resides. From a purely administrative perspective, mapping attributes to programs is problematic for many reasons. For example, students often claim advanced standing in their chosen program based on studies from elsewhere, programs often allow students a range of choice in actual course selection and even within courses some students will gain exemption from particular activities or not pass certain aspects of a course but nevertheless pass the course. Block exemptions (also termed block and/or credit transfer) for programs completed at other tertiary institutions are particularly problematic especially where the style of assessment is different (e.g. competency-based) or the culture and expectations are different (e.g. international students). Cross-institutional study (where students undertake courses at an institution different to the one offering their main set of courses) options further complicate the issue. Such arrangements have received much attention by individual institutions, accrediting bodies and government agencies but no linkage of the arrangements to or consideration of generic graduate attributes is obvious in the literature. Typically, students seek permission to undertake courses from institutions outside the certifying one but usually course content has been the main basis for the certifying institution agreeing to the study. In both these cases (block exemptions and cross-institutional study) it cannot be assumed, based on content, which the attributes, now expected of graduating students, have been met without closer examination of the outside courses and programs. In effect, for individual students it may be difficult to assess if they have attained the required attributes based on the courses done and grades obtained without an explicit supplementary assessment for attributes based on a portfolio supplied by students seeking exemptions or perhaps an assessment external to those currently conducted within courses.

Currently examiners of courses specify, through their stated course objectives, which graduate attributes are covered in their course and if they are assessed. Clearly, some examiners will be 
better able to specify objectives, some objectives are more easily assessed than others and some are more obvious than others. Snoke et al. (2002) have already indicated the need to 'enhance the objective writing skills' of academic staff conducting courses. Currently however, academic staff are not trained in this skill; in effect the content experts are simply expected to be able to write appropriate objectives. Accreditation committees review and comment on the objectives of programs and courses when they are presented to them and ensure graduate attributes are covered in the programs, but over time courses (and their objectives) change and, of course, corporate control at such a micro level is not possible or necessarily appropriate. Situations where it may be appropriate to exercise such control include core courses, particularly those utilised by several programs possibly over several disciplines and faculties.

\section{Graduate Attributes and Course Objectives}

Of course, writing better objectives that include attributes is one thing; incorporating teaching (and assessment) of these in current traditional teaching contexts is a greater challenge and one for which many academics are not prepared. For example, if teamwork is an important attribute (and it invariably is for IT/computing graduates) needing development and the teaching regime does not cater for it now how will it be incorporated? Who will teach the teachers? An approach that provides a more holistic view of teaching is problem-based learning where the focus is on learners rather than the teacher but not many academics are comfortable (or even know about) such approaches. Is the requirement to cover content compromised by the need to cover attributes?

With courses available in various modes of offer, including on-campus, external and on-line, it is likely that it may be felt that some attributes can and others cannot be included or considered covered in a particular offer of a course. In addition courses within a program are offered at various levels (typically 1-3 for a three-year program) and some attributes may be best developed early in a program, some late in the program, while others may need developing throughout a program. The extent of attribute coverage and level of attribute assessment can be gauged only by collecting and accumulating course specifications at the program level. Currently at USQ, there are no standards or benchmarks with respect to the level to which attributes are expected to be developed. The various policy development committees are aware of the issue of standards but a key question is who should define the standards: the university, disciplines, professions, industry, society, who?

Explicitly linking objectives to assessment is now expected of examiners and will find its way into course specifications and study materials accessible by students. Some objectives may be very difficult to assess or may need to be rewritten in a form that more easily permits assessment. The next step will almost inevitably involve linkage of objectives with graduate attributes: both generic and discipline-based. At this stage there is no intention to explicitly assess these attributes through the normal assessment process for courses or separately, but the linkage to objectives will enable implicit assessment of attributes. However, if attributes are not explicitly assessed how can they be assumed to have been developed? Many academics will see this as another administrative burden, perhaps even 'window dressing', even if there are benefits to the various stakeholders.

\section{Benefits of Attributes}

What are the benefits of defining attributes of a graduate (regardless of the fact they are required by government)? From a marketing perspective, universities can say their graduates have attribute $\mathrm{X}$. This may be an advantage, particularly to the innovators. Various stakeholders may be able to compare and contrast the attributes expected to be achieved by studying at particular institutions and in particular disciplines. Students could use this to select universities, employers could assess 
the potential graduates and comparisons will inevitably be made by the various producers of publications comparing universities.

Another benefit of explicitly stating graduate attributes is that debate can proceed more sensibly about the outcomes and expectations for the various stakeholders. Provided the attributes are stated in more than general terms, tertiary institutions can be held accountable for their claims. Courses need to state which objectives match which attributes and students can be prepared for assessments that test the criteria presented. Students are effectively forced to take heed of the objectives and focus their attention on them for assessment purposes. Society generally benefits through improved quality of graduates and by knowing the attributes expected. One question that might be raised here is 'which society?', particularly with the large numbers of international students now studying in Australia.

The extent to which the generic graduate attributes have actually been realised in this university's graduates is yet to be evaluated fully. Indeed some of the attributes may be difficult to measure and may need reconsideration. There may also be differences between students from different backgrounds. Nevertheless some limited evidence of attainment of the stated attributes is available from employers. Annual surveys of the destination of graduates are conducted and include questions to employers related to some of the graduate attributes including job skills (discipline knowledge), written communication and numeracy skills. Employers of Faculty of Business graduates (the data is not available in any finer detail) rate their employees as relatively high for these attributes. Employers are also able to provide comments/statements about their USQgraduated employees. These comments are available at the BIT program level and emphasise these attributes as well as others:

'... very pleased with the level of skills...'

'Able to think in depth. Strong in communication.'

'We are very satisfied with her performance ... her analytical skills.'

'Good communication skills and very willing to learn new skills.'

'... seems to be more liberal in terms of applying new techniques or considering new ideas.'

'Very willing to learn.'

'Improved skills in communication, management and analysing problems.'

\section{Comparison of Graduate Attributes}

The attributes as stated are generic and not meant to cover all attributes expected of graduates of specific disciplines. Universities might not necessarily be expected to produce graduates with the same graduate attributes but most discipline-based study should. Snoke \& Underwood (2001) have identified 29 attributes expected of IS graduates by industry and academe and they show how these stakeholders rank these attributes in terms of importance. Some are personal attributes such as 'self motivation' and 'time management skills' and it may be argued whether these can in fact be taught or whether only their principles can be taught. For example valuing ethical behaviours can be taught about but graduates cannot be made to behave ethically!

Examination of Snoke and Underwood's (2001) complete list of generic attributes and comparison with this university's graduate attributes shows all are covered except 'teamwork', 'research skills' and 'project management skills'. The highest ranked of these is 'teamwork' (rated 8 by industry and 1 by academics) and while it is covered in this university's IS curriculum, the other two attributes are less well covered (they rank in the 20 s by both groups so are clearly considered less important) and may be considered in a future re-examination of the curriculum. Interestingly, 
the university's graduate attributes were a subset of those of Snoke and Underwood (2001) with none extra or outside the set identified by them. However, one of the problems here is that stakeholders have different expectations. Snoke and Underwood (2001) found differences between industry and academe and Lynch and Collins (2001) found differences between some employers' and students' demands on the one hand and academe on the other in that the former were sometimes simply interested in the 'latest fad'. Most academics would argue the importance of teaching abstract concepts rather than specific tools/techniques. Some important attributes, such as oral communication and teamwork, are already incorporated in courses but many students comment negatively about their experiences in the academic context. Many international students have difficulties with oral and written communication - perhaps higher levels of English language ex-

pression might be one of their expected attributes on completion. Students sometimes go so far as to take courses in external or on-line modes to avoid these types of requirements that are often reserved for on-campus students.

An issue that follows from this identification by Snoke and Underwood (2001) of additional generic attributes for IS graduates is whether some of these should also be considered generic attributes for other graduates of this university. This is not an issue for this forum but there will certainly be ongoing debate at this university if not elsewhere about the appropriateness of the current set of generic attributes. Other attributes, for example 'international perspective' (AUQA, 2002) have already been suggested. Whether any subset can be distilled from universities more widely is also of interest.

Lastly, at least for the moment, is the issue of attributes in general. If graduate attributes are so important then what of high school graduate attributes? These represent admission requirements for universities. Already institutions are coping with the so-called Generation Y student cohort (Wolburg \& Pokrywczynski, 2001) with their short attention spans, challenging environments, demand for highly flexible programs of study, etc. What about mature-age entry attributes? What about attributes of postgraduates? Students are an important component in this debate but rarely are their situations analysed and dealt with fully.

\section{Conclusions and Future Research}

The issues raised in this paper are unlikely to be unique to the university considered - potentially, they are issues for all tertiary institutions because the various stakeholders make them so. Our colleagues agree, generic graduate attributes are workable, indeed according to our financial masters we must make them work, but many challenges are yet to be addressed.

With regard to the specific requirements of industry, in particular as articulated by the ACS, Snoke et al. (2002) have presented a methodology for universities to evaluate their IS curriculum. A cursory examination of their generic attributes (their Table 2) matched to USQ's graduate attributes indicates reasonable coverage although interpretation of the terms in both sets may need consideration. Further analysis is needed, however, particularly in the light of the pending review by ACS of IS programs (and Computer Science programs) offered at USQ and elsewhere.

Further research possibilities and questions have been hinted at already during discussion including the need to assess the range of generic attributes used across Australasia. Wider coverage than that is also envisaged with an examination of attributes of IS programs internationally. It is also of interest to investigate the expectations of overseas stakeholders given the large number of international students undertaking undergraduate studies in Australasia. 


\section{References}

Asmussen, K.J. \& Creswell, J.W. (1995). Campus response to a student gunman. Journal of Higher Education, 66, 575-591.

AUQA - Australian Universities Quality Agency (2002). Report of the Audit of University of Southern Queensland. Retrieved 4 March, 2004 from http://www.auqa.edu.au/qualityaudit/sai_reports/reports/auditreport_usq_2002.pdf

DEST (2001a). Research and research training management reports 2001 (Appendix). Retrieved 19 June, 2003 from http://www.detya.gov.au/highered/respubs/rrtm/files/appendix_grad_attributes.pdf

DEST (2001b). Graduate skills assessment summary report. Retrieved 1 December, 2003 from http://www.dest.gov.au/highered/occpaper/01e/default.htm

DETYA (1998). Research on employer satisfaction with graduate skills interim report, May, 98/8. Retrieved 1 December, 2003 from http://www.dest.gov.au/archive/highered/eippubs/eip988/execsum.htm

ECU (2003). Developing and maintaining units. Retrieved 4 March, 2004 from http://www.ecu.edu.au/LDS/rd/units/GAStaff.html

Lynch, J. \& Collins, F. (2001). From the horse's mouth: Factors inhibiting and driving innovation in ICT education. Proceedings of the Australian Association for Research in Education - AARE'01. Retrieved 18 June, 2003 from http://www.aare.edu.au/01pap/lyn01093.htm

Murdoch (2003). Mapping the graduate attributes. Retrieved 1 December, 2003 from http://www.tlc.murdoch.edu.au/gradatt/mapping.html

Nunan, T. (1999). Graduate qualities, employment and mass education, Proceedings of HERDSA 1999, Retrieved 2 March, 2004 from http://www.herdsa.org.au/branches/vic/Cornerstones/pdf/Nunan.PDF

Snoke, R. \& Underwood A. (1998). Generic attributes of IS graduates - A Queensland study. Proceedings of Ninth Australasian Conference on Information Systems, University of New South Wales, Sydney.

Snoke, R. \& Underwood, A. (1999). Generic attributes of IS graduates - An Australian IS academic study. Proceedings of Tenth Australasian Conference on Information Systems, Victoria University of Wellington, NZ, 817-824.

Snoke, R. \& Underwood, A. (2001). Generic attributes of IS graduates - A comparison of Australian industry and academic views. Journal of Global Information Management, 9 (2), 34-41.

Snoke, R., Underwood, A. \& Bruce, C. (2002). An Australian view of generic attributes coverage in undergraduate programs of study: An information systems case study. Proceedings of HERDSA 2002, 590598. Retrieved 4 March, 2004 from http://www.ecu.edu.au/conferences/herdsa/main/papers/ref/pdf/Snoke.pdf

Wolburg, J.M. \& Pokrywczynski, J. (2001). A psychographic analysis of Generation Y college students. Journal of Advertising Research, 41 (5), 33-52.

USQ (1999). An overview of USQ and its strategic direction. Planning and Statistics Unit, USQ.

USQ (2004). USQ calendar. Retrieved 3 March, 2004 from http://www.usq.edu.au/corporateservices/calendar/default.htm

Yin, R.K. (1994). Case study research: Design and methods. Thousand Oaks, CA, Sage Publications.

Yu, J., Hume, W.R., Lee, A. \& McConkey, K. (2002). Striving for quality: learning, teaching and scholarship. Submission to Higher Education Review Process Issues Papers: A submission from the University of New South Wales. Retrieved 4 March, 2004 from http://www.backingaustraliasfuture.gov.au/submissions/issues_sub/pdf/i31.pdf 


\section{Acknowledgements}

Many senior staff at USQ gave freely of their time in answering our questions related to the aims of this paper and their assistance is gratefully acknowledged. Feedback from several reviewers significantly improved this paper and their assistance is acknowledged also.

\section{Biography}

Mark Toleman is an Associate Professor of Information Systems at the University of Southern Queensland where he has taught computing subjects to engineers, scientists and business students for 18 years. He has a PhD in computer science from the University of Queensland and has published more than 60 articles in books, refereed journals and conference proceedings.

Dave Roberts is Head of Department, Information Systems at the University of Southern Queensland. He teaches mainly in the areas of systems analysis and design, as well as supervising postgraduate research students. Dave holds a MAppSc which focused on students' attitudes towards using computers. For the last 14 years, he has organized the Australian Computing Society's (ACS) computer competition. He selects and trains teams to represent Australia at the South-East Asian Regional Computer Confederation (SEARCC) programming competition. Dave is currently completing a $\mathrm{PhD}$ in the area of adoption of software upgrades.

Charmaine Ryan is Associate Head of Department, Information Systems at the University of Southern Queensland. Her teaching includes knowledge management systems and Visual Basic .NET, and she has research interests in knowledge management and human-computer interaction for information systems. Charmaine holds a MEd from the University of Queensland.

\section{Appendix}

\section{ATTRIBUTES OF A USQ GRADUATE}

\section{USQ Graduate Attributes}

- Graduates of USQ programs should possess the following attributes:

- competence and emerging expertise in their chosen discipline(s)

- analytical and critical-thinking skills

- problem-solving skills

- independent learning skills

- communication skills

- information technology literacy appropriate to their discipline(s)

- numeracy appropriate to their discipline(s)

- information acquisition, organisation and presentation skills

- decision-making skills based on open-mindedness, objectivity and reasoned analysis

- an awareness of the need for, and an understanding of, high professional standards and ethical behaviour

- an awareness of the need for, and an understanding of, individual responsibility and accountability

- an awareness that learning must be life long in an ever-changing society

- an understanding of the social, environmental and cultural context of their disciplines(s). 